\title{
Mulheres nas ciências: uma avaliação comparativa entre quatro cursos universitários
}

\author{
Women in sciences: a comparative evaluation between four university courses \\ Mujeres en ciencias: una evaluación comparativa entre cuatro cursos universitarios
}

Recebido: 19/07/2021 | Revisado: 25/07/2021 | Aceito: 12/09/2021 | Publicado: 13/09/2021

\author{
Thalyta de Oliveira Inocêncio \\ ORCID: https://orcid.org/0000-0003-2681-104X \\ Universidade Federal Rural do Rio de Janeiro, Brasil \\ E-mail: thalyta.96@hotmail.com \\ Ana Carolina Lucena Dias \\ ORCID: https://orcid.org/0000-0002-7330-8714 \\ Centro de Ensino Jacarepaguá, Brasil \\ E-mail: anacarolinafisica@gmail.com \\ Natalia Alves Machado \\ ORCID: https://orcid.org/0000-0003-2505-1800 \\ Universidade do Porto, Portugal \\ E-mail: nat.alves.machado@gmail.com \\ Frederico Alan de Oliveira Cruz \\ ORCID: https://orcid.org/0000-0002-2612-3952 \\ Universidade Federal Rural do Rio de Janeiro, Brasil \\ E-mail: frederico@ufrrj.br
}

\begin{abstract}
Resumo
"As ciências da natureza e a matemática são dominadas por homens!” Afirmações como essa levaram-nos a buscar dados que pudessem refutá-la ou confirmá-la. Por esse motivo, o presente trabalho traz uma análise do percentual de formação dos estudantes da Universidade Federal Rural do Rio de Janeiro dos cursos de licenciatura em Física, licenciatura e bacharelado em Matemática, Matemática/Computação, Química e Biologia, entre os anos 1989 e 2015. A análise desses dados não se limita apenas à exploração do número de formandos, mas também aos dados relativos ao quantitativo de docentes, pois buscamos ao longo do texto compreender questões como a compatibilidade - ou a falta dela entre os números de mulheres e homens formados e o quadro atual de docentes dos cursos analisados. Nesse percurso, foi mostrada a discrepância dos resultados, entre o gênero predominante de estudantes formados e docentes em cada um dos cursos, numa tentativa de alertar o leitor para um processo exclusivo, baseado no gênero (homens e mulheres cisgênero), recorrente nos níveis acadêmicos seguintes à graduação.
\end{abstract}

Palavras-chave: Mulheres na ciência; Ciências naturais e matemática; Gênero.

\begin{abstract}
"Natural sciences and mathematics are dominated by men!" Statements like this led us to seek data that could refute or confirm it. For this reason, the present work presents an analysis of the percentage of education of students at the Federal Rural University of Rio de Janeiro in Physics, Licentiate and Bachelor's Degree in Mathematics, Mathematics/Computer, Chemistry and Biology, between 1989 and 2015. The analysis of these data is not limited only to the exploration of the number of graduates, but also to the data related to the number of teachers, as we seek throughout the text to understand issues such as compatibility - or the lack of it between the numbers of women and men graduates and the current faculty of the analyzed courses. Along this route, the discrepancy of the results was shown, between the predominant gender of graduate students and professors in each of the courses, in an attempt to alert the reader to an exclusive process, based on gender (cisgender men and women), recurrent in academic levels following graduation.
\end{abstract}

Keywords: Women in science; Natural sciences and mathematics; Gender.

\section{Resumen}

“¿Las ciencias naturales y las matemáticas están dominadas por los hombres!” Declaraciones como esta nos llevaron a buscar datos que pudieran refutarlo o confirmarlo. Por ello, el presente trabajo presenta un análisis del porcentaje de educación de los estudiantes de la Universidad Federal Rural de Río de Janeiro en Física, Licenciatura y Licenciatura en Matemáticas, Matemáticas / Computación, Química y Biología, entre 1989 y 2015. El El análisis de estos datos no se limita solo a la exploración del número de graduados, sino también a los datos relacionados con el número de docentes, ya que buscamos a lo largo del texto comprender cuestiones como la compatibilidad, o la falta de ella entre los números. de egresados y alumnas y el cuerpo docente actual de los cursos analizados. En esta ruta, se mostró la discrepancia de los resultados, entre el género predominante de estudiantes de posgrado y profesores en cada uno de 
los cursos, en un intento de alertar al lector sobre un proceso exclusivo, basado en el género (hombres y mujeres cisgénero), recurrente en los niveles académicos posteriores a la graduación.

Palabras clave: Mujeres en ciencia; Ciencias naturales y matemáticas; Género.

\section{Introdução}

É inegável a necessidade de repensar como as escolas e as universidades oferecem a educação para a população, visto que, em função dos desafios impostos para a atual sociedade, é necessário que homens e mulheres possam estar aptos a agir nos momentos de crise e, também, trabalhar em conjunto para o desenvolvimento da comunidade. Isso é perceptível na “Agenda para o Desenvolvimento Sustentável”, assinada em 2015, que estabeleceu dezessete Objetivos de Desenvolvimento Sustentável (ODS), visando promover a erradicação da pobreza, o desenvolvimento equilibrado e ambientalmente responsável (Figura 1). No que foi estabelecido, o Objetivo 4, intitulado "Educação de Qualidade", traz entre suas propostas (ONU, 2015):

4.1 Até 2030, garantir que todas as meninas e meninos completem o ensino primário e secundário livre, equitativo e de qualidade, que conduza a resultados de aprendizagem relevantes e eficazes

4.2 Até 2030, garantir que todos os meninos e meninas tenham acesso a um desenvolvimento de qualidade na primeira infância, cuidados e educação pré-escolar, de modo que estejam prontos para o ensino primário

4.3 Até 2030, assegurar a igualdade de acesso para todos os homens e mulheres à educação técnica, profissional e superior de qualidade, a preços acessíveis, incluindo universidade

4.5 Até 2030, eliminar as disparidades de gênero na educação e garantir a igualdade de acesso a todos os níveis de educação e formação profissional para os mais vulneráveis, incluindo as pessoas com deficiência, povos indígenas e as crianças em situação de vulnerabilidade

4.6 Até 2030, garantir que todos os jovens e uma substancial proporção dos adultos, homens e mulheres, estejam alfabetizados e tenham adquirido o conhecimento básico de matemática.

Figura 1 - Representação das 17 ODS presentes na Agenda 2030.

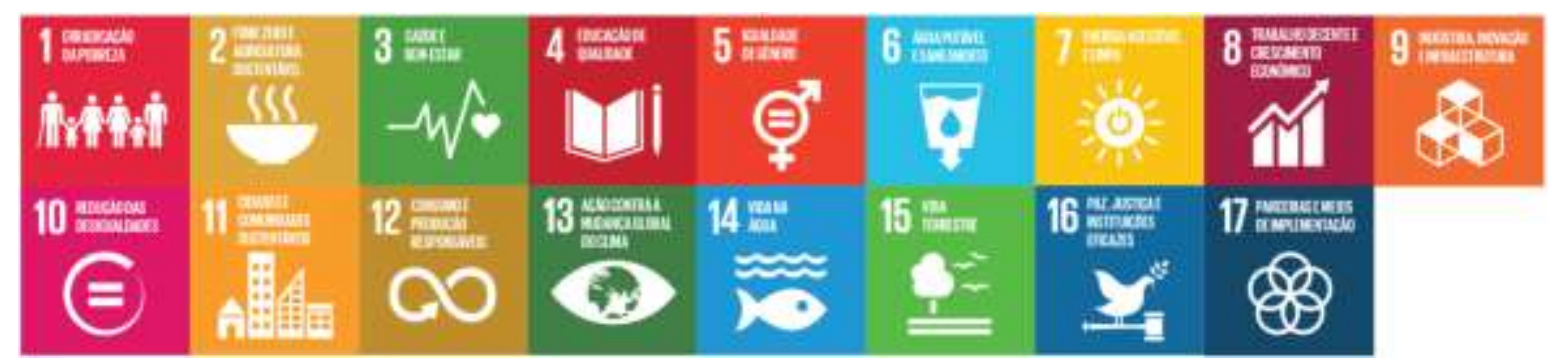

Fonte: ONU (2015).

A questão é que parece haver certo desequilíbrio prejudicial entre homens e mulheres em determinadas áreas da ciência, onde constata-se "pouca presença feminina", que se torna "um problema para todos, porque perde-se o potencial intelectual das mulheres" (Abc, 2020). Esse cenário é real, como mostrado no trecho a seguir:

[...] é um padrão universal que atinge diversos campos. Mas, dentro das ciências naturais, há desníveis muito acentuados. Por exemplo, na área da biologia, há um equilíbrio maior, que diminui na química e se mantém desigual na física. Portanto, a baixa presença de mulheres é um padrão que não vem de hoje (ibidem)

Sendo assim, é importante determinar em quais condições isso ocorre, pois essa cultura impeditiva pode acontecer dentro das famílias, das escolas, das universidades ou em todos esses espaços. Ao entender o problema, será possível criar ações que visem contemplar a ODS 5 (ONU, 2015), ou seja: “Alcançar a igualdade de gênero e empoderar todas as mulheres e meninas". 


\section{Entendendo o Cenário da Distribuição de Gênero: População, Educação, Trabalho e Renda}

A sociedade brasileira atual - considerando o ano de 2020 como referência - possui aproximadamente 210 milhões de habitantes, sendo o número de mulheres e homens distribuído da seguinte forma (Ibge, 2020a):

Segundo dados da PNAD Contínua (Pesquisa Nacional por Amostra de Domicílios Contínua) 2019, o número de mulheres no Brasil é superior ao de homens. A população brasileira é composta por 48,2\% de homens e 51,8\% de mulheres. Na faixa etária até 24 anos, os homens tiveram estimativa superior à das mulheres. Totalizaram, em 2019, $17,8 \%$, contra $17,2 \%$ da população feminina da mesma faixa etária. Por outro lado, a partir dos 25 anos de idade, a proporção de mulheres era maior que a dos homens em todos os grupos de idade.

Em relação ao nível de escolarização, tema de muitos trabalhos ao longo dos últimos anos (Barroso, Mello, 1975; Beltrão, Alves, 2009; Leone, Baltar, 2006; Leone, Portilho, 2018; Rosemberg, 2009), foram ressaltados na pesquisa realizada pelo IBGE os seguintes dados (Ibge, 2020b):

Quanto à educação, mostra-se uma tendência geral de aumento da escolaridade das mulheres em relação aos homens, sendo que as mulheres atingem em média um nível de instrução superior ao dos homens. Entre os homens com 25 anos ou mais de idade, $13,5 \%$ têm ensino superior completo. Já entre as mulheres com 25 anos ou mais de idade no país, $16,9 \%$ completaram o ensino superior.

No que diz a respeito à carga de trabalho semanal, um elemento que influencia questões relacionadas ao bem-estar e horário disponível para a educação, a distribuição ocorre de maneira bastante desigual (Ibge, 2020b):

Em 2016, os homens dedicaram em média 10 horas e meia por semana aos cuidados de pessoas e/ou afazeres domésticos, enquanto o tempo dedicado pelas mulheres a estas tarefas foi de cerca de 18 horas por semana. Mulheres que precisam conciliar trabalho remunerado com os afazeres domésticos e cuidados, em muitos casos, acabam tendo empregos com menos horas semanais. Enquanto 14,1\% dos homens estavam em empregos de até 30 horas semanais, 28,2\% das mulheres das tinham empregos com até esta carga horária.

Percebe-se também, nesse cenário, que quando a mulher se insere em espaço laboral tradicionalmente ocupado por homens, ocorre, como mostrado por Daniel (2011), a "sexualização do local e da relação de trabalho", imposição às "mulheres a execução de tarefas mais complexas" e penalização mais rigorosa pelos erros por elas cometidos em comparação aos cometidos pelos homens (ibidem, p. 338). Segundo Andrade (2016, p. 54):

As mulheres são o grupo mais vulnerável ao assédio, seja moral ou sexual. Ambos causam impactos negativos profundos às trabalhadoras, acarretando-lhes estresse emocional, perda do poder de concentração, transtornos de adaptação, ansiedade, insegurança, baixa autoestima, faltas ao trabalho, perdas de produtividade e perda de motivação.

O termo "impacto negativo", usado por Andrade (2016), merece uma breve discussão, pois o assédio é tipificado no código penal da seguinte forma: "Art. 216-A. Constranger alguém com o intuito de obter vantagem ou favorecimento sexual, prevalecendo-se o agente da sua condição de superior hierárquico ou ascendência inerentes ao exercício de emprego, cargo ou função" (Brasil, 2001) isto é, essas mulheres são vítimas recorrente de crimes e parece haver um conformismo social que aceita o fato de que os responsáveis não são punidos.

Além disso, apesar da escolarização das mulheres ser ligeiramente maior que a dos homens, a renda não apresenta a mesma disparidade, pois muitas vezes elas são obrigadas a ocupar cargos com menor qualificação, consequentemente, com menores salários. Isso fica claro a partir dos dados do IBGE (2020b), ao mostrar que o salário médio mensal das mulheres é cerca de $25 \%$ menor que o dos homens (figura 2). Essa situação, que parece permear todas as áreas da sociedade, é marcante 
também nas universidades, onde se percebe uma forte presença masculina no corpo docente. Como mencionado por Cunha, Miranda e Rambo (2020, p. 279):

[...] em países como a Alemanha (33\%), na Finlândia (29\%), na Hungria e no Luxemburgo (ambas com 25\%) as mulheres representam menos de um terço do quantitativo global de cientistas. Por outro lado, na América Latina e no Caribe, as mulheres representam $45 \%$ dos pesquisadores científicos, com $36 \%$ nas disciplinas STEM (sigla para Ciência, Tecnologia, Engenharias e Matemática) (ibidem).

Esse fato pode indicar a existência de um processo excludente dentro de certos cursos universitários, que dificulta (ou até mesmo impede) a formação das mulheres e favorece a dos homens, num local em que se espera um predomínio de ações críticas e progressistas.

Figura 2 - Comparativo entre o salário médio dos trabalhadores brasileiros e o salário mínimo em 2019.

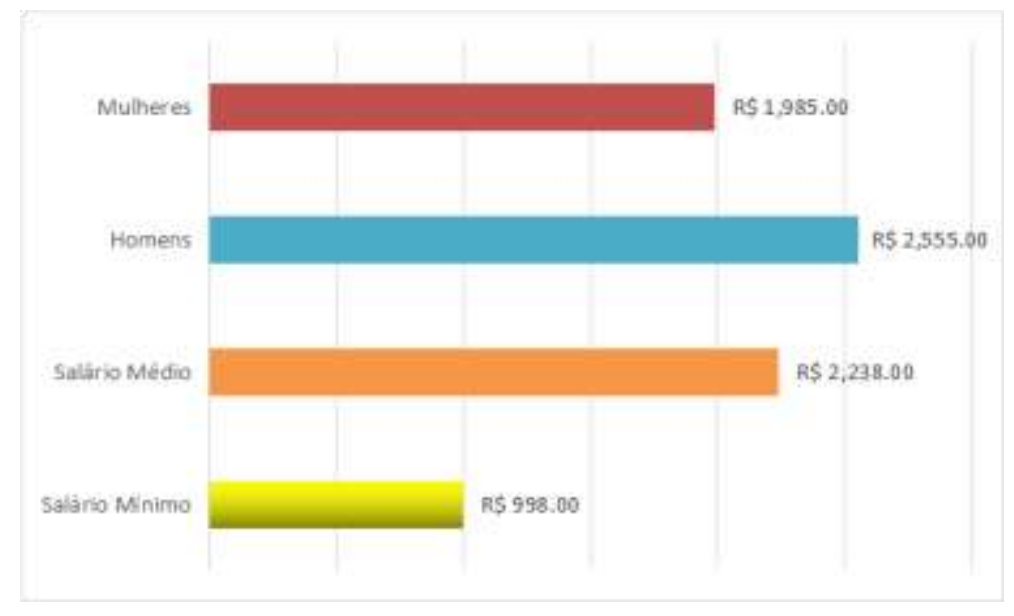

Fonte: IBGE (2020b).

\section{Metodologia de Análise}

Apesar de considerarmos como ciências todas as áreas de conhecimento, limitamos a nossa análise aos cursos de Biologia, Química, Física e Matemática. Para que fosse possível realizar a análise proposta neste trabalho, foi solicitado à PróReitoria de Graduação da Universidade Federal Rural do Rio de Janeiro (UFRRJ) a relação dos formandos em cada um dos cursos selecionados, disponíveis no sistema eletrônico da universidade até o ano de 2015. A escolha pelo ano citado foi realizada considerando que cada um dos cursos possui um tempo de integralização de pelo menos quatro anos (ou oito períodos) e assim poderia haver cursos em que os ingressantes, em 2016, ainda não teriam se formado até o final de 2019 (ano que os dados foram solicitados), causando uma percepção equivocada da situação. Os dados fornecidos pela universidade também apresentam uma variação quanto ao ano do início da análise: enquanto em alguns casos existem dados disponíveis a partir de 1989, em outros apenas a partir da década de 90, pois neste período o sistema da universidade ainda não era digital e muitos dados não foram inseridos nas novas plataformas de informação.

De posse dos dados, foi realizada uma tabulação da seguinte forma: ano de ingresso, número de homens e mulheres que conseguiram concluir o curso de escolha. A avaliação do tempo de formação não foi realizada, pois esse não era o foco do trabalho, e sim considerar a quantidade de estudantes de um determinado ano de ingresso que foram capazes de concluir o curso. Em seguida, foram construídos, para cada um dos casos, gráficos dos discentes formandos, divididos em gênero (consideramos aqui apenas homem e mulher, não fazendo distinção entre cis e trans, uma vez que os dados disponíveis não forneciam essas informações), em relação ao ano de ingresso. 
Como elemento comparativo, também foi avaliado o perfil do corpo docente dos cursos supracitados, com o objetivo de analisar se o processo de exclusão é marcante durante toda a formação ou se ele está associado a determinadas fases da vida profissional.

\section{Resultados e Discussão}

A apresentação da análise dos dados foi organizada em tópicos, para facilitar a discussão e compreensão do leitor, permitindo que as particularidades de cada curso sejam abordadas de uma forma mais direta e baseadas em discussões apresentadas por outros autores. É importante ressaltar que na estrutura administrativa da UFRRJ, os departamentos de física, matemática e computação estão inseridos no Instituto de Ciências Exatas. No entanto, a separação ocorreu apenas para que pudessem ser avaliadas as diferenças entre as áreas do conhecimento.

\subsection{A falta de mulheres na Física}

A Física, notoriamente, é uma carreira com prevalência de homens. No trabalho de Londero, Sorpreso e Santos (2014) é citada uma reportagem, de outubro de 2013, sobre um levantamento na rede pública de ensino estadual de São Paulo, no qual "a disciplina de física é a única com mais professores homens (53\%). No entanto, no panorama geral, os homens correspondem a 26,2\% dos profissionais da rede estadual de educação" (ibidem, p. 382).

A realidade dos profissionais da física está associada à menor quantidade de mulheres formadas nos cursos de licenciatura em comparação ao número de homens, como pode ser verificado no trabalho de Barreto (2014) e também observada na avaliação dos dados fornecidos pela Pró-Reitoria de Graduação da UFRRJ, em que, apesar do aumento de mulheres formadas ao longo dos anos, este número ainda é insuficiente para superar o número de homens formados (Figura 3).

Figura 3 - Distribuição de discentes que concluíram a Licenciatura em Física, considerando o ano de ingresso.

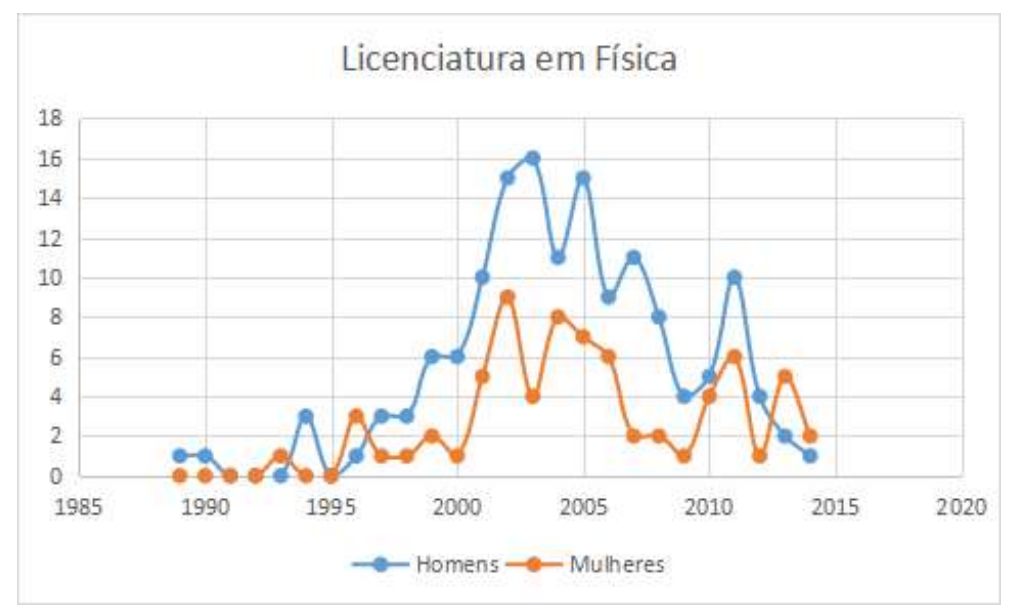

Fonte: UFRRJ (2020).

Ao longo dos anos avaliados, o percentual de homens formados foi em torno de $67 \%$ e o de mulheres de aproximadamente $33 \%$, ou seja, o número de homens formados é o dobro do quantitativo de mulheres, dados que corroboram a percepção de que existem poucas mulheres nos cursos de Física de forma geral e que essa disparidade se perpetua (Cartaxo, 2012). Esse fato pode indicar que a escolha da formação em física pode estar sendo influenciada por outros fatores, como dito por Souza (2015):

[...] o processo de escolha profissional é influenciado pela família e pela sociedade, e que a importância dada a esses 
fatores pode guiar o indivíduo para determinada profissão. Foi ressaltado por uma das respondentes que a pressão dos pais, muitas vezes, acaba forçando o indivíduo a fazer um curso não desejado. Dessa forma, infere-se que as questões de gênero é uma faceta, dentre muitas, envolvida na escolha profissional. (ibidem, p. 30)

No caso do corpo docente do Departamento de Física, da mesma universidade, o quantitativo de homens é praticamente dez vezes maior que o de mulheres (Figura 4), indicando uma possível perpetuação, de uma forma ainda mais drástica, do cenário visto nos dados daqueles que concluíram o curso de Licenciatura em Física (Sigaa, 2021).

Figura 4 - Distribuição dos docentes do Departamento de Física da UFFRJ.

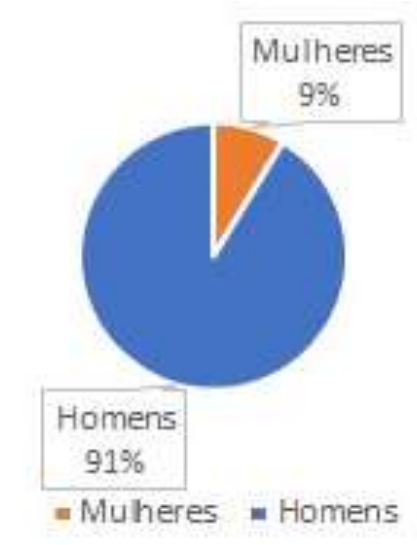

Fonte: SIGAA (2021).

\subsection{A Matemática está em mais equilíbrio, mas apenas entre os formandos.}

No curso de Matemática a realidade se mostra um pouco mais equilibrada, em comparação ao curso de Física, pois o número de concluintes é razoavelmente equivalente entre os gêneros. Na avaliação das habilitações existentes para os cursos de Matemática - Licenciatura (Figura 5), Computação (Figura 6) e Bacharelado (Figura 7) - o número global de formandos é de aproximadamente $45 \%$ de mulheres e $55 \%$ de homens. É importante salientar que o número relativamente maior de formandos relacionados aos ingressantes no ano de 2005 está muito associado às políticas de expansão universitárias ocorridas a partir de 2003, no governo do então Presidente Luiz Inácio Lula da Silva, e da estabilidade econômica do país naquela época, que provocou uma maior procura pelas provas de acesso universidades em todo país até o ano de 2012 como mostrado a seguir:

[...] as matrículas em cursos presenciais no ensino superior cresceram de 3.887.022 em 2003 para 5.923 .838 em 2012 , o que corresponde a um crescimento de mais de 52\% no período. Ainda segundo o INEP, em 2003, 2.750 .652 matrículas em graduações presenciais eram em Instituições de Ensino Superior (IES) privadas (71\% do total) e 1.136.370 (29\% do total) nas públicas. (BD, 2014) 
Figura 5 - Distribuição de discentes que concluíram a Licenciatura em Matemática, considerando o ano de ingresso.

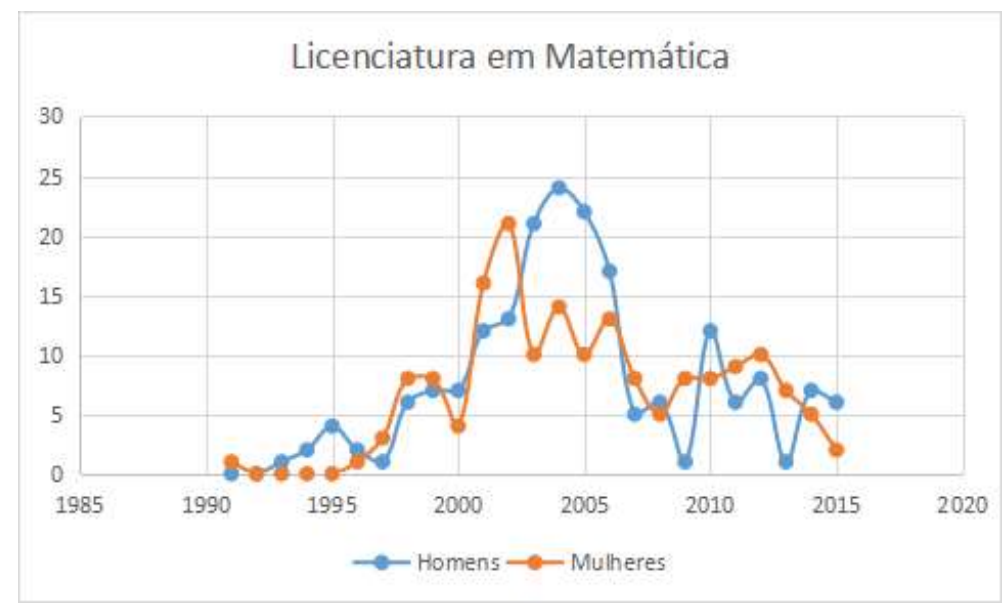

Fonte: UFRRJ (2020).

Figura 6 - Distribuição de discentes que concluíram o Bacharelado em Matemática/Computação, considerando o ano de ingresso.

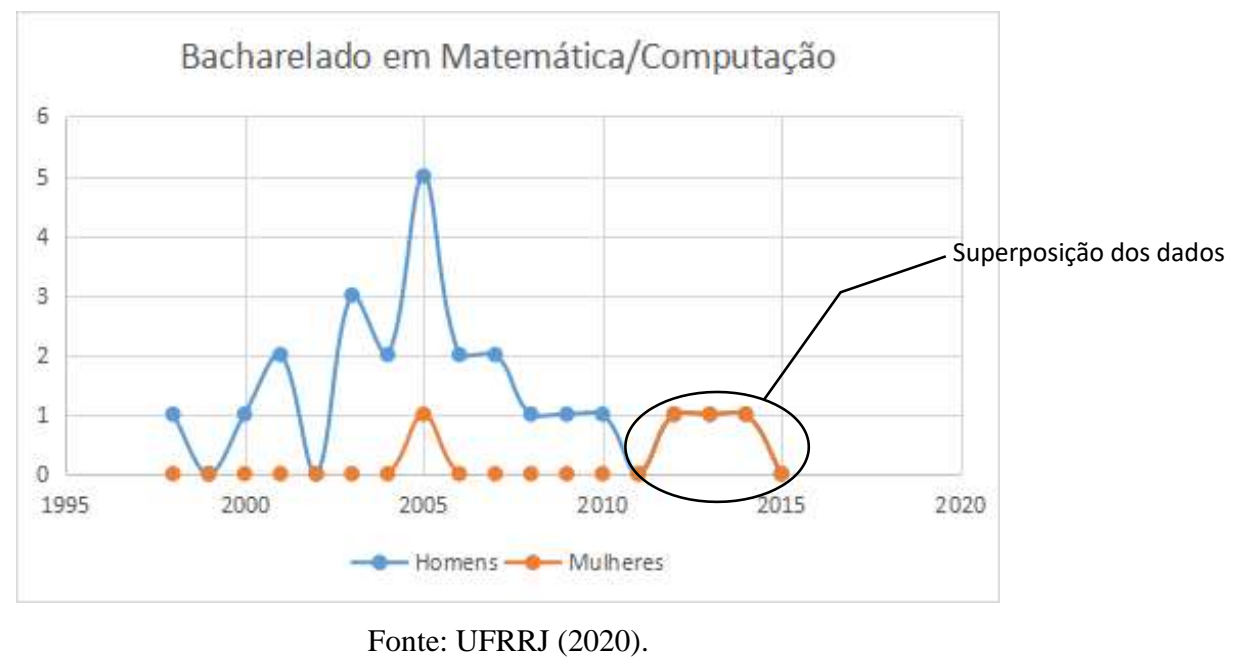

Figura 7 - Distribuição de discentes que concluíram o Bacharelado em Matemática, considerando o ano de ingresso.

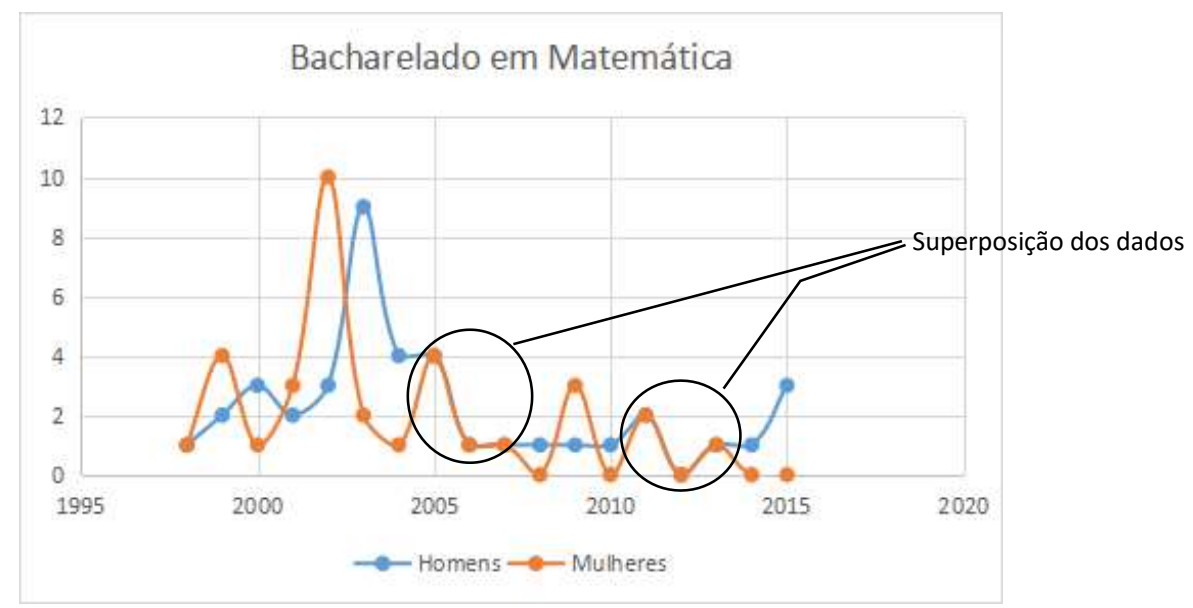

Fonte: UFRRJ (2020).

Se avaliarmos apenas os dados do curso de licenciatura em Matemática, é fácil perceber um certo equilíbrio entre os concluintes dessa habilitação, fato esse que corrobora os já apresentados por Assis (2020), numa análise realizada sobre os 
discentes do curso de licenciatura em Matemática do IES-BA. Observa-se aqui o fato de que o equilíbrio não está no "curso" de Matemática, mas no fato de ser licenciatura, ou seja uma formação para a docência em ensino básico que apresenta historicamente uma maior presença de mulheres. Como mostrado recentemente por Gorziza, Piltcher e Buono (2021):

O Brasil é um país de professoras: elas são $81 \%$ dos docentes de escolas regulares, técnicas e EJA, de acordo com dados do Censo Escolar de 2020 [...] A presença de mulheres diminui à medida em que avança o nível das etapas de ensino. Mulheres correspondem a $96 \%$ dos professores da educação infantil. No ensino fundamental I e II, elas representam, respectivamente, $88 \%$ e $67 \%$ dos docentes. No ensino médio, o percentual diminui para 58\%. (ibidem)

Em relação ao curso de Computação, a presença maciça de discentes homens pode estar associada a alguns fatores culturais atuais, como a consideração de que o mundo digital um espaço vinculado a "eles", que têm uma relação com os jogos digitais até certo ponto incentivada pelas famílias. Apesar de se verificar uma maior inserção de mulheres nesses espaços, a permanência nem sempre é duradoura, posto existir uma cultura de assédio que atua como fator decisivo para esse afastamento das mulheres em relação aos games (Bristot, Bozzebon, Frigo, 2017), o que pode gerar um impacto na escolha da carreira profissional.

O distanciamento desse público de determinados ambientes, seja ele devido ao assédio ou não, também é verificado quando observamos o corpo docente do curso de Matemática, onde parece haver uma propagação da diferença quantitativa entre homens e mulheres observada na habilitação de computação, mas não nas relacionadas diretamente com a Matemática. Na avaliação a partir das informações do Sistema Integrado de Gestão de Atividades Acadêmicas (Sigaa, 2021), foi possível perceber uma grande diferença entre os gêneros (Figura 8), mesmo que menor em comparação ao curso de Física. Apesar de ambos os cursos possuírem o mesmo tempo de duração e estarem dentro da mesma grande área de conhecimentos - Ciências Exatas e da Terra - a distorção encontrada é muito significativa.

Figura 8 - Distribuição dos docentes do Departamentos de Matemática e Computação.

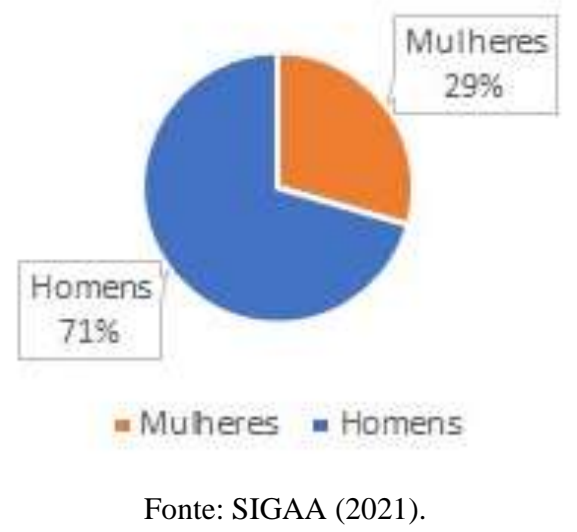

\subsection{A prevalência de mulheres formadas em Química, em contraste com o corpo docente.}

Se na Matemática e na Física o número de homens é superior ao de mulheres, nos cursos de Química - seja na licenciatura ou no bacharelado - a situação é inversa. A proporção de diplomados ao longo dos anos analisados mostra que aproximadamente $56 \%$ são mulheres, com uma prevalência delas em relação a eles em quase uma década inteira (Figura 9 , figura 10). No caso do curso de bacharelado, especificamente, o número de formandos de mulheres quase sempre foi maior que de homens, com um pouco mais de equilíbrio na habilitação em licenciatura, realidade contrastante com os resultados percebidos para os cursos de Física e Matemática, indicando que existe um ambiente mais propício para as discentes prosseguirem o curso ou existem fatores externos, não associados ao ambiente acadêmico, que influenciam nessa continuidade. 
Figura 9 - Distribuição de discentes que concluíram o Bacharelado em Química, considerando o ano de ingresso.

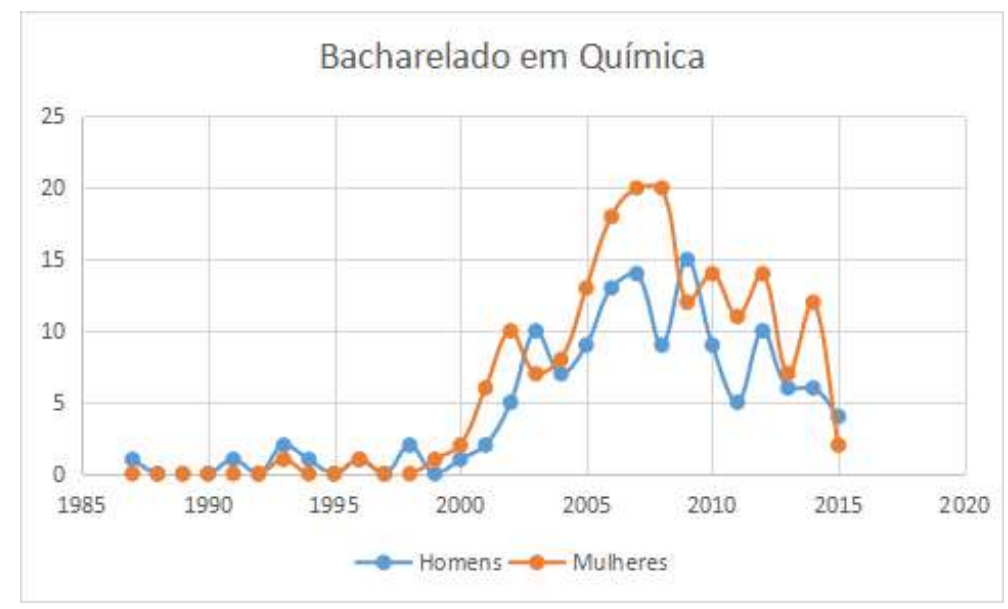

Fonte: UFRRJ (2020).

Figura 10 - Distribuição de discentes que concluíram a Licenciatura em Química, considerando o ano de ingresso.

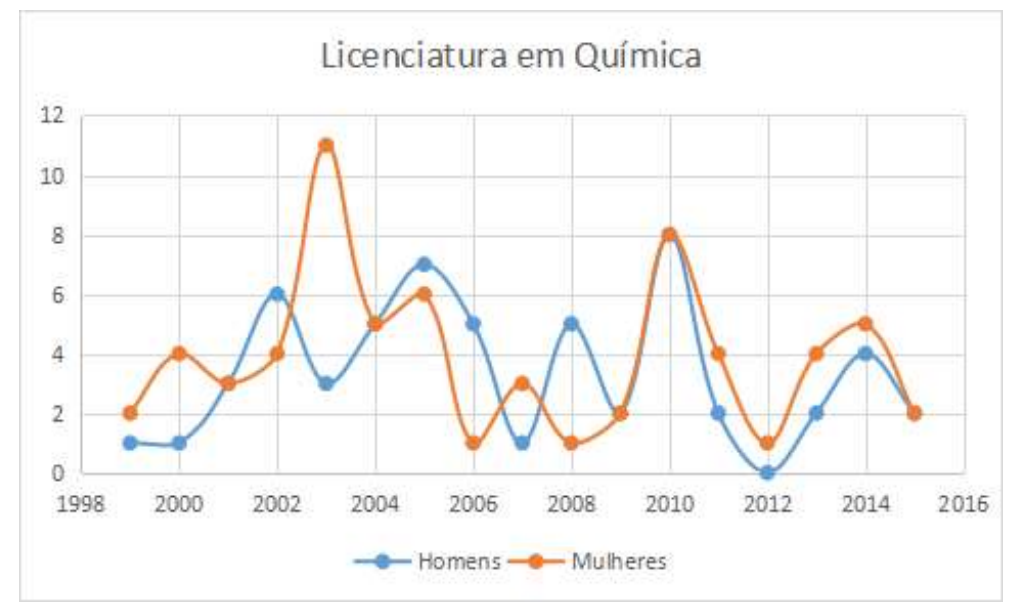

Fonte: UFRRJ (2020).

Os dados aqui apresentados são condizentes com a realidade do mercado de trabalho, apesar de serem níveis de escolarização distintos, Souza e Salgado (2017, p. 43) afirmam que: “O número de Técnicas em Química, respondentes da pesquisa nas empresas avaliadas, é de 1,77 vezes maior do que o número de Técnicos em Química”. Contudo no caso do corpo docente do Instituto de Química da UFRRJ - composto atualmente pelos departamentos de Bioquímica, Físico-Química, Química Analítica, Química Orgânica, Química Inorgânica - novamente percebe-se um predomínio de docentes homens (Sigaa, 2021), contrastando com a realidade de um maior número de concluintes mulheres (Figura 11). 
Figura 11 - Distribuição dos docentes do Instituto de Química.

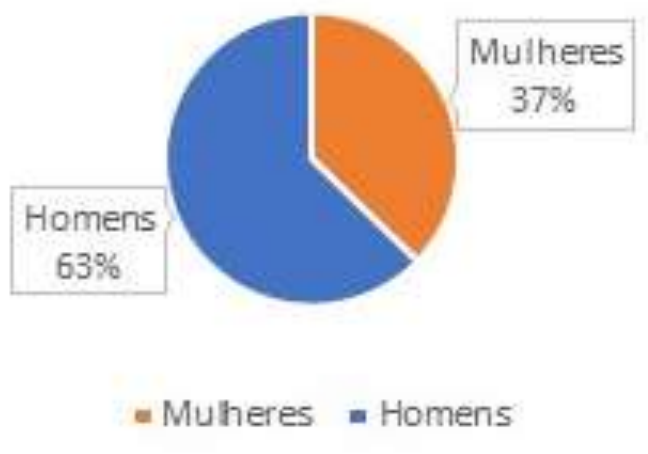

Fonte: SIGAA (2021).

Os dados apresentados na Figura 11 são compatíveis aos mostrado no trabalho de Naideka et al. (2020), como pode ser percebido no seguinte trecho:

[...] o número de pesquisadores registrados no Conselho Nacional de Desenvolvimento Científico e Tecnológico (CNPq) em 2018, nas áreas de química, física e matemática existe uma disparidade de gênero, em que 68\% é composto por homens e $32 \%$ por mulheres. Ao analisar as principais áreas da química: físico-química, orgânica, analítica e inorgânica, observa-se um valor crescente de representatividade feminina como pesquisadoras, indo de 25 a $35 \%$ na ordem citada para as respectivas áreas. (ibidem, p. 823)

\subsection{A biologia é o curso com mais mulheres, mas nem tanto.}

A graduação em Biologia, somando-se as duas habilitações disponíveis, apresenta a maior diferença entre gêneros em relação aos cursos analisados, com aproximadamente 70\% dos concluintes sendo mulheres (Figura 12, Figura 13) - o oposto do que foi percebido nos cursos de Física e Matemática - mas apresentando uma tendência mais próxima daquela vista nos cursos de Química.

Figura 12 - Distribuição de discentes que concluíram a Licenciatura em Biologia, considerando o ano de ingresso.

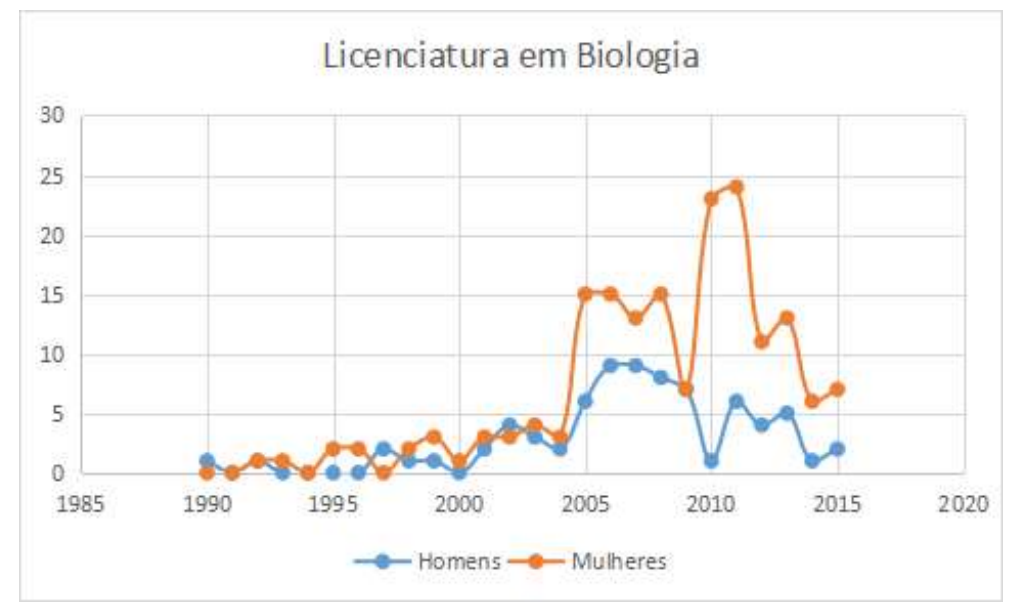

Fonte: UFRRJ (2020). 
Figura 13 - Distribuição de discentes que concluíram o Bacharelado em Biologia, considerando o ano de ingresso.

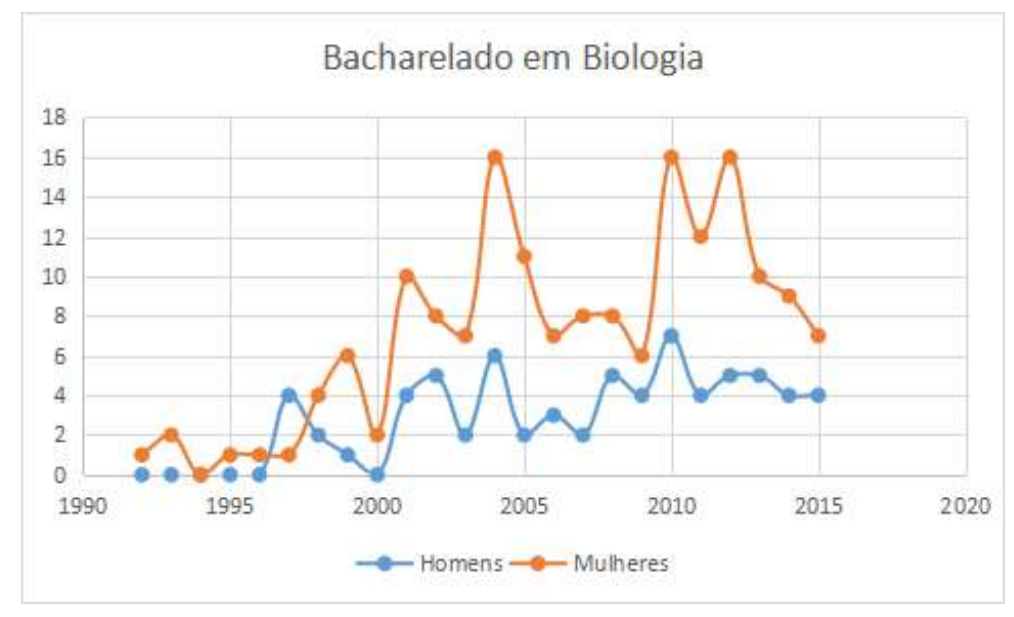

Fonte: UFRRJ (2020).

Outro ponto relevante é que o resultado encontrado na análise dos formandos está de acordo com os dados de uma pesquisa realizada pelo Centro de Estudos Políticos e Sociais (2014, apud Santos, Tortato 2018), que mostra que:

[...] o percentual de mulheres matriculadas nas Universidades Federais era de 52,37\%, sendo que os maiores fluxos de matrículas giravam em torno dos cursos das Ciências da Saúde, Linguística, Letras, Artes, Ciências Biológicas, Ciências Humanas e Ciências Sociais Aplicadas; enquanto nas Ciências Agrárias o percentual de homens e mulheres matriculados se mantinha, praticamente, o mesmo. (ibidem, p. 41)

Quando voltamos o nosso olhar para a análise do corpo docente do Instituto de Biologia - composto pelos departamentos de Anatomia Animal e Humana, Biologia Animal, Botânica, Ciências Farmacêuticas, Ciências Fisiológicas, Entomologia e Fitopatologia, e genética - nota-se que essa diferença não é tão acentuada (Figura 14), havendo um equilíbrio entre o quantitativo de docentes homens e mulheres (Sigaa, 2021).

Figura 14 - Distribuição dos docentes do Instituto de Biologia.
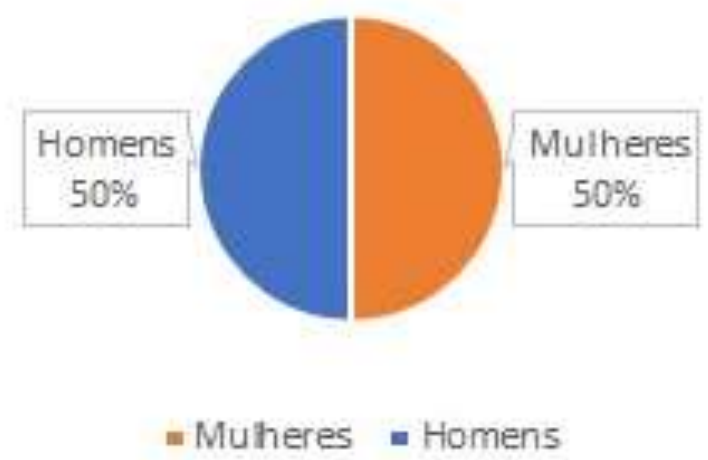

Fonte: SIGAA (2021).

No entanto, percebe-se que:

Nos últimos 20 anos, as diferenças entre gêneros em termos de acesso à educação diminuíram sensivelmente na maioria dos países da América Latina. Entre os alunos matriculados no ensino superior, a participação dos gêneros é equilibrada ou, até mesmo, favorável às mulheres [...] À medida que aumenta a hierarquia em termos de progresso nas carreiras científicas, nota-se um decréscimo substancial do número de mulheres. (ibidem, p. 116) 
Uma possível explicação para a diminuição gradual, entre o número de formandos e profissionais atuantes nas instituições, pode estar associada a comportamentos similares ao das áreas já mencionadas, mas que são minimizados por uma presença maior de mulheres nas ciências biológicas, como citado por Santos e Tortato (2018, p. 55):

Nas Ciências Biológicas, o preconceito de gênero manifesta-se de maneira diferente, mais contido, em formas de comentários, "brincadeiras" e dúvidas em relação à realização de algumas tarefas. É um preconceito sutil, que nem todas as mulheres são capazes de identificar, pois é tudo tão naturalizado que, muitas vezes, acaba-se pensando que não há uma necessidade de problematizar essas questões. Afinal, as mulheres são maioria. E é justamente esse entendimento que colabora para o que acontece nas Ciências Biológicas permaneça tácito.

\subsection{Fazendo uma análise geral}

Quando se olha para o quadro geral, o número de mulheres que se formam nos cursos aqui analisados é maior que o percentual de homens (Figura 15). Apesar da prevalência de homens de forma significativa no curso de licenciatura em Física, e de certo equilíbrio no curso de Matemática, nas áreas de Biologia e Química o predomínio de mulheres (é importante ressaltar que os dados se referem às mulheres cis, como já mencionado anteriormente) justifica o resultado encontrado, contrariando a visão geral de um quantitativo maior de homens do que mulheres formados nas Ciências Naturais e Matemática.

Figura 15 - Distribuição de discentes que concluíram em todos os cursos avaliados, de 1989 até 2015.

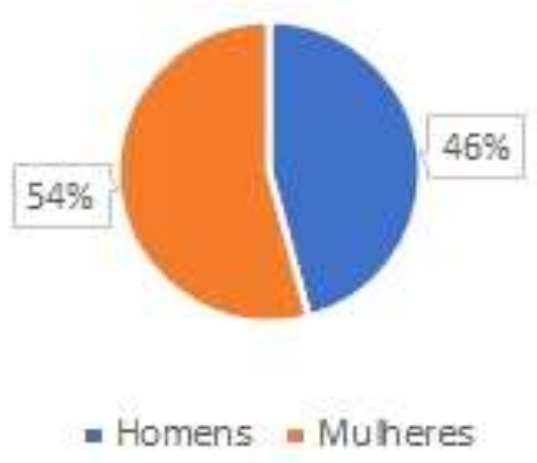

Fonte: SIGAA (2021).

Contudo, ao analisarmos de forma geral o percentual de docentes homens e mulheres, a realidade é contrária àquela mostrada entre os concluintes (Figura 16). Esses resultados estão em consonância aos dados apresentados por Venturini (2017) onde se "constata uma diferença de quase 10 pontos percentuais na participação de homens e mulheres. Dados do Censo da Educação Superior divulgados pelo INEP indicam que em 2015 os homens representavam 54,61\% dos docentes em exercício e as mulheres $45,39 \%$. ." (ibidem, p. 11). 
Figura 16 - Distribuição de docentes dos cursos avaliados.

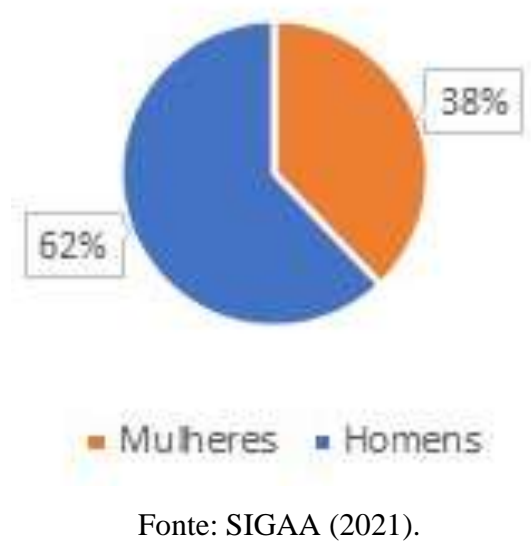

Esses resultados mostram que o ingresso na carreira docente universitária, um dos cargos de docência com melhor remuneração do país, ainda mantém uma predominância de profissionais homens, corroborando a ideia trazida por Ferrari et al. (2018 apud Cunha, Miranda, Rambo, 2020, p. 277) que "a concentração de homens aumenta à medida que se avança na carreira científica”. Essa discrepância entre o percentual de mulheres formadas e atuantes na carreira docente nos indica que existe um processo de exclusão, relacionado ao gênero, no prosseguimento da vida profissional.

\section{Considerações Finais}

Para que possamos compreender os resultados apresentados podemos considerar o ponto de vista, trazido por Lima $e t$ al. (2017) ao realizar a seguinte afirmação:

[...] o gênero torna-se uma barreira e traz limitações bastante marcantes no processo de escolha profissional e no desenvolvimento de carreiras. Pode-se ver, ainda, que padrões de gênero são fatores importantes na delimitação de atividades cotidianas e na definição do status do lugar ocupado na organização familiar, condicionando a formação de vínculos sociais. (ibidem, p. 40)

Nota-se que, pelo menos no quadro analisado na UFRRJ, as barreiras para a escolha dos cursos não foram impactantes, pois exceto o curso de Licenciatura em Física, os demais cursos apresentam uma presença marcante das mulheres. No entanto, é visível que, caso essa análise fosse propagada aos níveis mais altos da carreira, deveria haver pelo menos uma proporção razoável de homens e mulheres docentes, o que não acontece, podendo ser um indicativo de que no processo de continuidade na carreira científica ocorre, após a formação no ensino superior, uma exclusão das mulheres na ascensão à carreira docente. O tema já foi abordado por Saitovitch, Lima e Barbosa (2015, p. 3) ao mostrarem que:

Os dados mundiais mostram que o percentual de mulheres diminui à medida que avançam na carreira. Este fenômeno foi observado em um estudo detalhado realizado pelo Grupo de Helsinki (HELSINKI,2001, EU-MEMBER-STATES, 1999) e é conhecido como "Scissors Diagram" como forma de ressaltar que as mulheres são cortadas para fora da carreira. Este fenômeno é igualmente denominando pelo Banco Mundial de "The leaky pipe line" (HUYER, 2015), pois as mulheres evadem da carreira como a água de um cano com vazamento, representando uma perda de mão de obra qualificada relevante. [...] Os obstáculos em relação à exclusão vertical têm sido representados como "Teto de Vidro", sob o qual estariam as barreiras à ascensão das mulheres na carreira científica. A transparência do vidro é uma metáfora para a suposta invisibilidade destes obstáculos, uma vez que estes não são de ordem formal, ou seja, não há impedimento legal para a maior participação das mulheres em postos de poder [....]

Baseando-se no que foi exposto até aqui, o foco da discussão também deve buscar compreender como as 
universidades estão formando seus profissionais e assim entender por que esse processo de exclusão permanece como uma cultura sem fim, sendo possível estabelecer ações que possam dar um fim a esse cenário, contribuindo para a criação de ambientes laborais menos nocivos e mais produtivos. Por fim, consideramos que algumas ações poderiam ser feitas no intuito de mudar o atual cenário:

$\checkmark \quad$ Os professores do corpo docente do curso deveriam envolver-se mais em projetos de extensão interdisciplinares ou de iniciação científica, que abordem temas relacionados com a presença das mulheres nas ciências, aumentando a visibilidade do protagonismo feminino na construção da ciência;

$\checkmark$ Necessidade de valorização das cientistas mulheres, que muitas vezes são responsáveis por teorias e teoremas presentes nas ciências, mas que, ao contrário dos homens, não ganham o devido protagonismo. Uma citação sobre o pesquisador em questão, antes de apresentar um tema, poderia ajudar nessa visibilidade;

$\checkmark$ O diálogo entre professores e alunos deve ser melhorado e incentivado, pois diminuindo-se a desvalorização do pensamento feminino, as situações de assédio e de discursos carregados de preconceitos poderiam ser enfraquecidas;

$\checkmark$ Os cursos devem ter representação estudantil forte, que preze pelos direitos dos estudantes e tenham fóruns sérios de discussão sobre comportamentos abusivos, por parte dos professores e de outros estudantes, sendo possível promover um espaço de apoio e de denúncia desses comportamentos.

\section{Agradecimentos}

Os autores agradecem à Universidade Federal Rural do Rio de Janeiro pelo apoio, à Profa. Dra. Fafate Costa, ao Prof. Dr. Cláudio Maia e à Psicóloga Karoline Arcanjo pelas leituras e sugestões na escrita deste trabalho.

\section{Referências}

Abc - Academia Brasileira de Ciências. (2020). Ronald Shellard: “a pouca presença feminina na fisica não reflete a proporção das mulheres na sociedade”. https://is.gd/0Vc3ZA.

Assis, E. S. (2020). As relações de gênero na licenciatura em matemática. Revista RBBA, 9(1): 54-78.

Andrade, T. (2016). Mulheres no mercado de trabalho: onde nasce a desigualdade? Brasília: Câmara dos Deputados - Estudo Técnico.

Barreto, A. (2014). A mulher no ensino superior distribuição e representatividade. Cadernos do GEA, 6: 5-45.

Barroso, C. L. M., \& Mello, G. N. O. (1975). Acesso da mulher ao ensino superior brasileiro. Caderno de pesquisa, $15:$ 47-77.

Beltrão, K. I., Alves, J. E. D. (2009). A reversão do hiato de gênero na educação brasileira no século XX. Caderno de Pesquisa, 39(136): 125-156.

BD - Brasil Debate. (2014). Matrículas no ensino superior crescem 52\% de 2003 a 2012. https://is.gd/M4d5aA

Brasil (2001). Lei n. 10.224, de 15 e maio de 2001. Altera o Decreto-Lei no 2.848, de 7 de dezembro de 1940 - Código Penal, para dispor sobre o crime de assédio sexual e dá outras providências. https://is.gd/bUWZhw

Bristot, P. C., Bozzebon, E., \& Frigo, L. B. (2017). A Representatividade das Mulheres nos Games. Proceedings of SBGames 2017. p. 862-871.

Cartaxo, S. M. C. (2012). Gênero e ciência: um estudo sobre as mulheres na Física. [Dissertação de Mestrado, Universidade Estadual de Campinas].

Cunha, U. F. C., Miranda, C. M., \& Rambo, M. K. D. (2020). Mulheres nas ciências exatas e tecnologias: um olhar para a Universidade Federal do Tocantins - UFT na perspectiva de gênero. Revista Humanidades e Inovação, 7(2): 276-289.

Daniel, C. (2011). O trabalho e a questão de gênero: a participação de mulheres na dinâmica do trabalho. O Social em Questão, 14(25/26): 323-344.

Gorziza, A., Piltcher, A. S., \& Buono, R. (2021). Brasil tem mais docentes mulheres do que homens. https://is.gd/VEZDmh

Ibge - Instituto Brasileiro de Geografia e Estatística. (2020a). Quantidade de homens e mulheres. https://is.gd/fCpcuv.

Ibge - Instituto Brasileiro de Geografia e Estatística. (2020b). Mulheres brasileiras na educação e no trabalho. https://is.gd/1Wll1B.

Leone, E. T., \& Baltar, P. (2006). Diferenças de rendimento do trabalho de homens e mulheres com educação superior nas metrópoles. Revista brasileira de estudos populares, 23(2): 355-367. 
Research, Society and Development, v. 10, n. 12, e58101218428, 2021

(CC BY 4.0) | ISSN 2525-3409 | DOI: http://dx.doi.org/10.33448/rsd-v10i12.18428

Leone, E. T., Portilho, L. (2018). Inserção de mulheres e homens com nível superior de escolaridade no mercado de trabalho brasileiro. Temáticas, 26(52): $227-246$.

Lima, F. I. A. et al. (2017). A influência da construção de papeis sociais de gênero na escolha profissional. Revista Brasileira de Psicologia e Educação, 19(1): 33-50.

Londero, L., Sorpreso, T. P., Santos, D. M. (2014). Mulheres na licenciatura em física: uma permanência limitada. Revista Tecné, Episteme y Didaxis, Extraordinario: 381-389.

Naidek, N. et al. (2020). Mulheres cientistas na química brasileira. Química Nova, 43(6): 823-836.

Onu - Organização das Nações Unidas. (2015). Objetivo 4: Educação de Qualidade. https://is.gd/PIfDje.

Saitovitch, E. B., Lima, B. S., Barbosa, M. C. (2015). Mulheres na Física: Uma análise quantitativa. https://is.gd/siefS5.

Santos, M., Tortato, C. S. B. (2018). Ciências Biológicas: mais mulheres, menos preconceito? Cadernos de Gênero e Tecnologia. 11(37): 40-59.

Sigaa - Sistemas Integrado de Gestão de Atividades Acadêmicas. (2021). Pesquisa do corpo docente dos departamentos da UFRRJ. https://is.gd/qTbtP9.

Souza, M. L. R. S. (2015). Gênero e escolha profissional. [Monografia de Especialização, Universidade de Brasília].

Souza, A. B., Salgado, T. D. M. (2017). Diferenças entre gênero na carreira do técnico em química: dos bancos escolares à atuação. Revista Thema, 14(3): 3749.

Ufrrj - Universidade Federal Rural do Rio de Janeiro. (2020). Relatório de Concluintes.

Venturini, A. C. (2017). A presença das mulheres nas universidades brasileiras: um panorama de desigualdade. Anais do Mundos de Mulheres \& Fazendo Gênero. p. 1-15. https://is.gd/ip4n7O 